IN THE Red CRoss World

\title{
MEETING OF RED CROSS VOLUNTARY WORKERS
}

From 9 to 14 April 1972, Singapore was the venue for the International Friendship and Training Camp for Red Cross Volunteers from Indonesia, Malaysia, Thailand and Singapore. Nearly sixty people participated, and the ICRC was represented by Mr. B. Daniel, delegate, who delivered an address on the International Red Cross, the ICRC's current activities, and the Geneva Conventions.

The work programme enabled everyone to forge many personal contacts and each National Society to describe first its organization and activities, and secondly the practical work carried out by its voluntary members. For example:

Indonesia gave an account of volunteer training in Djakarta and the provinces;

Malaysia, the operations undertaken by its voluntary workers in the fields of first-aid and disaster relief, particularly during floods;

Thailand, the essentially social work of its volunteers; and

Singapore, the work of its Voluntary Aid Detachment in first aid and relief, particularly in the event of fire.

In addition, the National Societies presented reports on the moral significance of voluntary work and the importance of the voluntary worker's practical contribution to the accomplishment of the Red Cross ideal. That contribution is essential, and the Indonesian Red Cross submitted a study entitled "The Volunteer, a Great Potential " concluding with the sentence: "It is for the Red Cross to understand that without the combat force of volunteers, the Red Cross will never win war against disaster". 